\title{
Guide to Blogging in Economics
}

Original authors: Paul Ayres, Intute Social Sciences, University of Bristol and Bhagesh Sachania, The Economics Network, University of Bristol

Updated version published February 2009, published in CHEER journal Volume 20, pages 32-37, ISSN 1358-5363

2016 version by Martin Poulter, The Economics Network

\section{Contents}

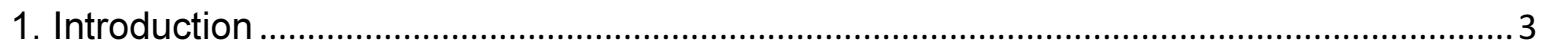

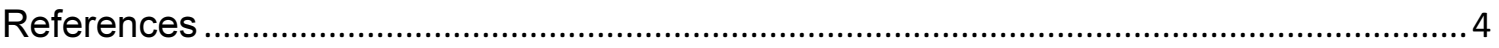

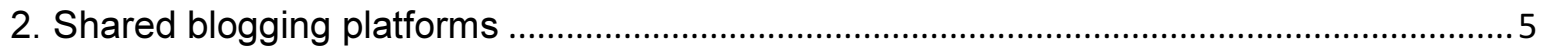

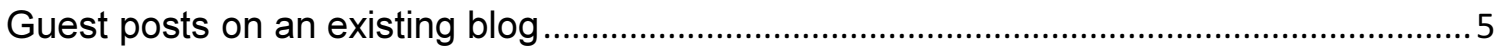

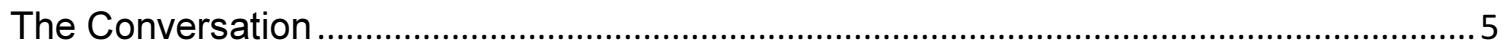

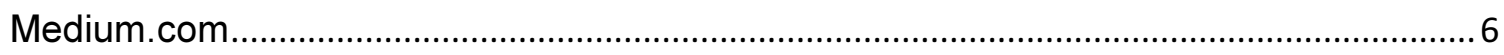

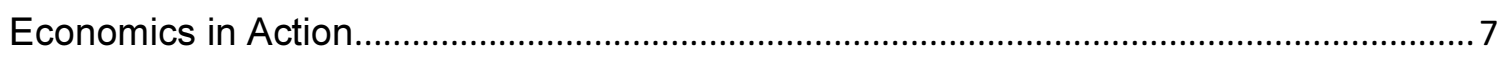

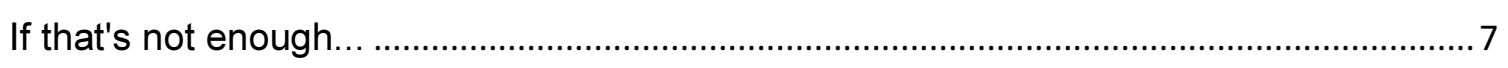

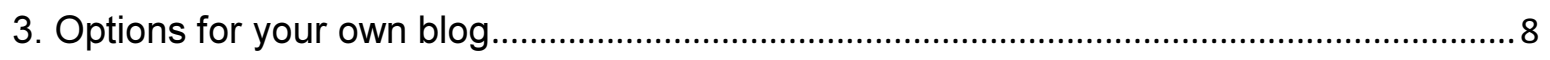

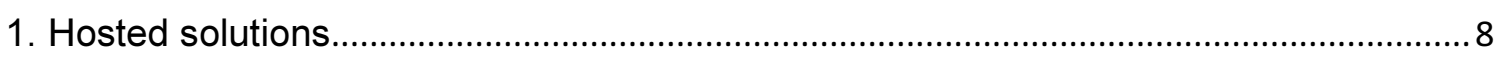

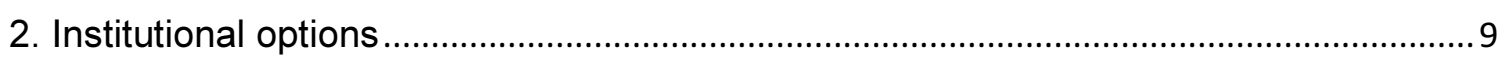

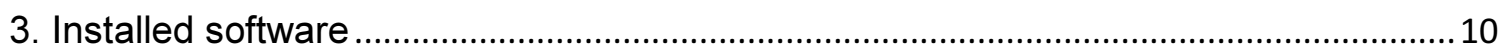

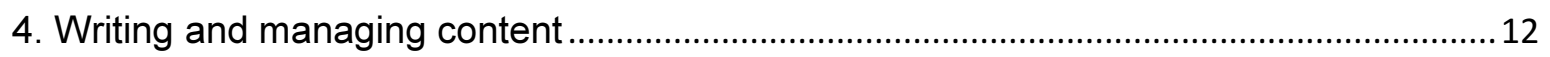

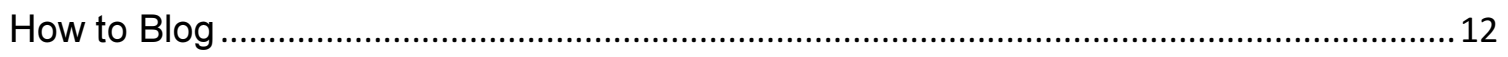

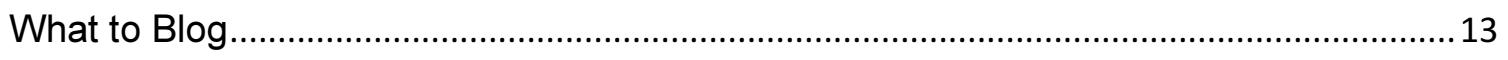

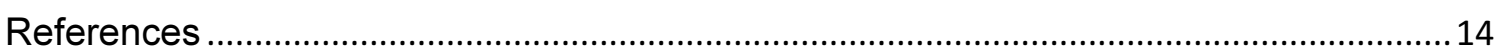

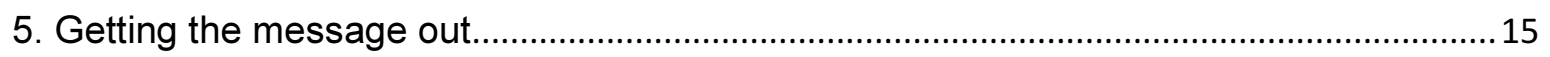

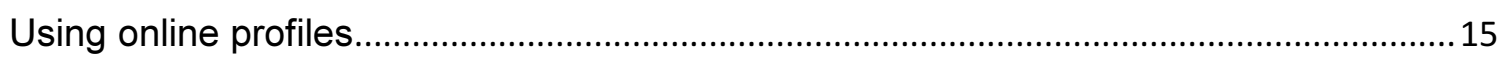

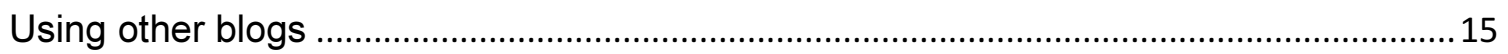

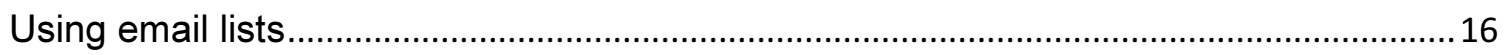

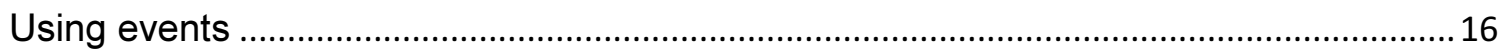

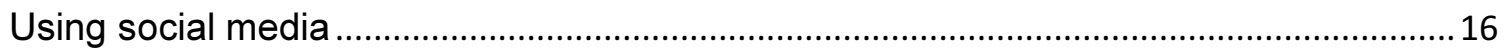

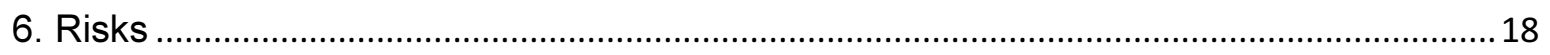

Effect on your job, or your next job....................................................................... 18

Relationship with your institution..................................................................... 18 


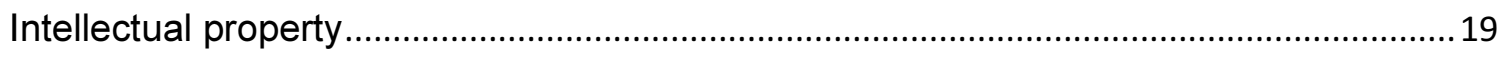

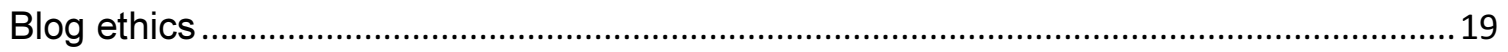

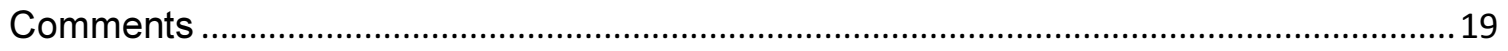

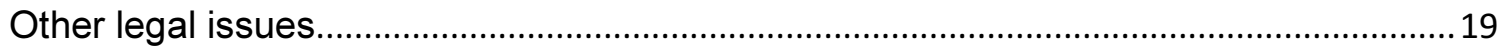

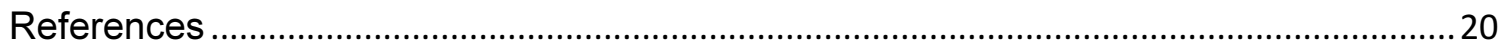

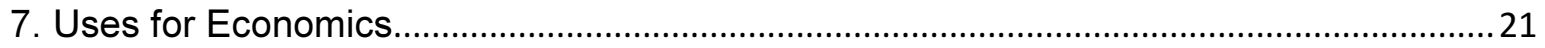

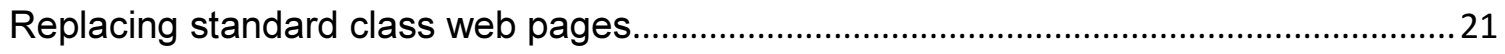

Professor-written blogs which cover interesting developments that relate to the theme of

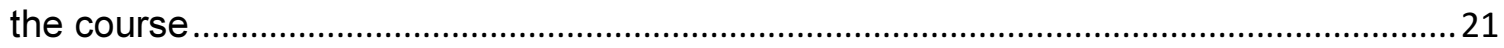

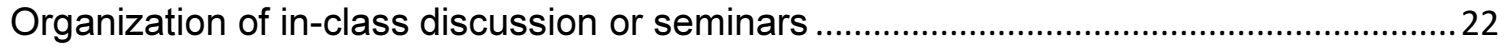

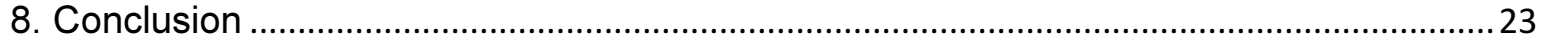




\section{Introduction}

" 'I certainly have not found a comparable way to get my ideas out. It allows me to have a voice I would not otherwise get,' Mr [Brad] Setser says. Blogs have enabled economists to turn their microphones into megaphones." -"The invisible hand on the keyboard", The Economist, 3 August 2006

A blog is, in essence, an online diary-style website. Simple software enables writers to create short articles in a form, and publish at the press of a button. It is a quick-and-easy way to publish on the web without having to be a web geek. The articles appear on the site in chronological order, with the most recent at the top of the page. As time goes on, they are automatically archived by date and by topic.

What is the case for blogging among the economics community? One of the best known blogging economists, Brad DeLong of the University of California at Berkeley, says that blogging gives him access to an "invisible college" of people who will react to his opinions, point him to more interesting things, help him to raise the level of debate on economic issues and bring it to a mass audience. He neatly sums up blogging as "turbo charging of the public sphere of information and debate", which he hopes will make him smarter and more productive.

Blogs do this by being interactive. This takes many forms including: providing links to other websites, papers or blogs; allowing readers to comment on articles; producing a network of links, relationships and interactions across the web.

"Academically a blogpost boosts citations for the core article itself. It advertises your journal article in ways that can get it far more widely read than just pushing the article out into the ether to sink or swim on its own. A post reaches other researchers in your discipline. And because it's accessibly written, it travels well, goes overseas, gets re-tweeted and re-liked," writes Patrick Dunleavy of the LSE.

FT columnist Giles Wilkes reflects on various failings of the economics "blog-o-sphere", but still praises it for an unmatched insight into what the great minds of the day are thinking about.

"[I]ts ungated to-and-fro lets a reader eavesdrop on schools of academic thought in furious argument, rather than just be subject to whatever lecture a professor wishes to deliver. No one learns merely by reading conclusions. It is in the space between rival positions that insight sprouts up, from the synthesis of clashing thoughts."

Blogs have been around since the late 1990s according to blog pioneer Rebecca Blood, but took a while to go mainstream. In the US Presidential election of 2004 they began to be used as a major source of online news. Blogs behave in accordance with a power law whereby a small number of blogs enjoy a large 
amount of influence, but a "long tail" of lower-ranked blogs collectively have a huge readership.

This guide has some useful pointers for newcomers to the world of blogging. It will start with the assumption that you have something to say; something that can be digested into a short article. It might be an update about your own research, or a reaction to current events. It could be a summary or critique of a paper or a book that you've been reading. It might be in a polished style, or a note-form list of things you've been reading or thinking about.

In the rest of this guide we will look at how to get this message out to an audience of fellow economists and lay people. We will explain different blogging platforms, but grisly technical detail will be unnecessary. Finally we will focus on specific uses of blogs in economics and some case studies of how they are used in teaching.

\section{References}

- "Blog" / Wikipedia

- $\underline{B l o g s} /$ from The Economist

- Power Laws, Weblogs and Inequality / Clay Shirky, 2003

- The Internet and Campaign 2004 / Pew Internet Research Center

- The Invisible College / J. Bradford DeLong, 2006

- How I learnt to love the economic blogosphere / Giles Wilkes, 2016

- State of the Blogosphere, 2008 / Technorati.com

- Weblogs a history and perspective / Rebecca Blood, 2000 


\section{Shared blogging platforms}

Let's say you want to get your views out without setting up a blog. Perhaps you don't ever intend to run your own blog. Alternatively, you might consider starting a blog, but want to dip your toe in the water first, seeing how an audience reacts. There are various ways to get your essay to an existing audience.

\section{Guest posts on an existing blog}

When somebody has an established blog, they need a regular stream of new and interesting posts to maintain their audience. So it's an attractive option to host relevant one-off posts by guest authors. Some blogs welcome guest posts: others only publish the designated author or group of authors. It's entirely up to the blog owner.

So, you might be welcome as a guest author on someone's blog, but scattershot, unsolicited offers to write will get lost amongst the spam. Instead, follow your favourite blogs, offer constructive comments, and get to know what topics the blog owners are interested in and if they ever host guest posts. Get your name known to the owner(s) before contacting them to suggest the specific topic or perspective you could write about.

Be prepared for the response "I don't want to post that on my blog, but if you post it elsewhere, I'll link to it and discuss it." In this case, consider one of the publishing options below or in the next section.

\section{The Conversation}

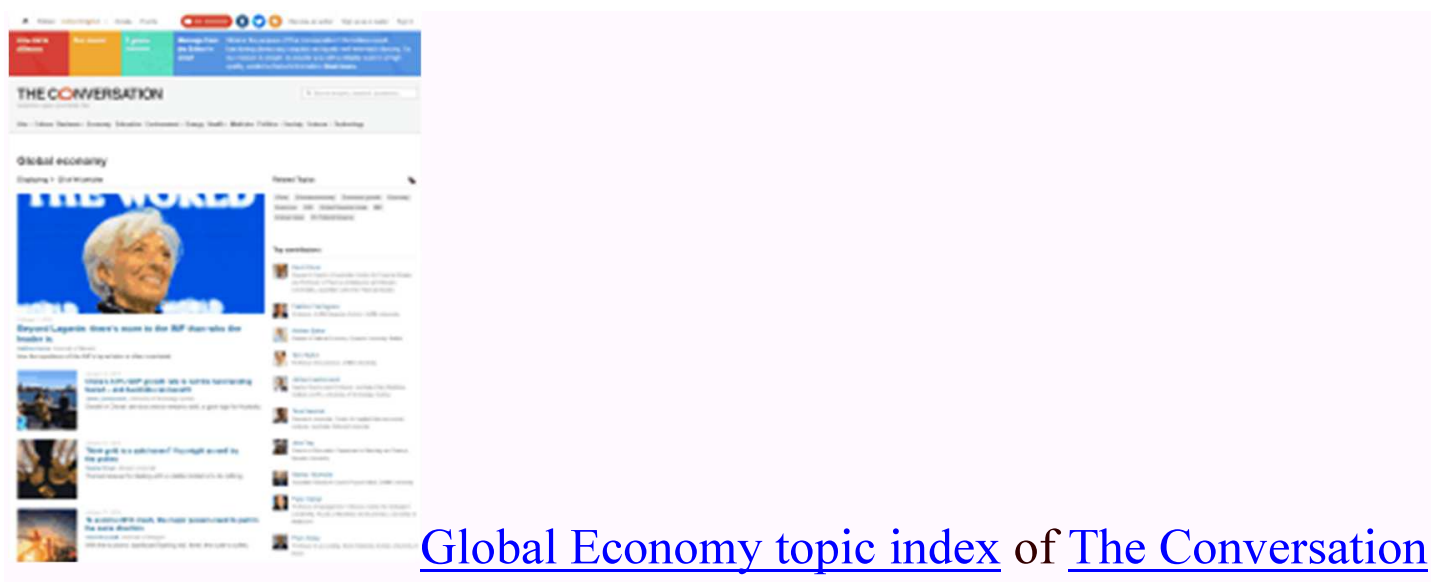

The Conversation is run by a consortium of universities and its aim is captured in the slogan "Academic rigour, journalistic flair". It provides commentary on all sorts of topical issues, written by qualified academic experts but for a lay audience. Articles might be topical in the sense of reacting to news such as a Budget 
statement, or in the sense of giving an "explainer" in advance of the event to set out its context.

You can register as a contributor, declaring your academic post and qualifications, through a form on the site.

If your university is part of the consortium, your press office may already be in touch with The Conversation, promoting the expertise of the university's staff. It can be a good idea to make yourself known to the press office, telling them the issue you'd be interested in writing about if the opportunity arises. Bear in mind that the site's topical focus means you may have to write a piece at short notice.

The Conversation has a Creative Commons Attribution NoDerivatives licence, so posts from the site can be reused, unaltered, elsewhere. For example, if newspapers want an opinion column on a topical issue, they can copy from The Conversation, but must attribute the author.

\section{Some economics posts on The Conversation:}

- "NHS outpaces the UK economy in productivity gains" by Andrew Street and Katja Grasic

- "Explainer: how does the weather affect the economy?" by Geraint Johnes

- "There hasn't been any austerity in the UK - and that might explain the upturn" by W. David McCausland

\section{Medium.com}

Medium is a platform on which people can submit, share and comment on essays, and where readers can tailor the kind of essays that are visible to them. Think of it as like Twitter but with essay-length posts. In fact, if you have a Twitter account, you can use it to $\log$ in to Medium.

As well as a distinctive, readable, look, Medium has popularised some novel ways to interact. Readers can comment on specific places in the text, not just at the foot of the page. They can also bookmark and share highlighted quotes from the text. At the time of writing, the site is free and without adverts. It remains to be seen what will change as they come under pressure to monetise.

Authors have a variety of licensing options on Medium. The site does not claim any rights to users' posts, and it is possible to select a Creative Commons licence which allows reuse on other sites and publications.

\section{Some economics posts on Medium:}

- "Thoughts on 'Teaching Economics after the Crash'" by Karl Whelan 
- "Why The 3 Men Who Violently Robbed Me Are Bad At Economics" by Ezra Winter

- "Self-Driving Trucks Are Going to Hit Us Like a Human-Driven Truck" by Scott Santens

\section{Economics in Action}

To complete this section, a word from our sponsors. The Economics Network's site for prospective students, Why Study Economics?, runs a blog showing real-world illustrations of economic concepts. It welcomes guest posts from academics who want to raise interest in the modules they teach. Authors of relevant books have contributed passages from the book or e-mail interviews as blog posts. Contact econ-network@bristol.ac.uk to suggest a post.

\section{If that's not enough...}

In this section, we've looked at existing platforms to get your ideas out to a wide audience. Perhaps you would prefer something more strongly connected to your own name (or your project's name); part of your official web presence rather than your text on someone else's site. Or perhaps you have a specific need such as a course blog that only your students can comment on. If so, read the next section about setting up your own blog. 


\section{Options for your own blog}

Once you have decided to start your own blog, you need to ask yourself:

- Do you have technical support available, or do you want maximum ease?

- Do you want a customised design, or are you happy to choose from some templates?

- Is an ordinary blog enough, or do you have specific needs such as a multiauthor or password-protected blog?

Your answers affect whether it will be better to use a commercial service, your own server, or an institutional platform.

\section{Hosted solutions}

Hosted software is where a company has set up blogging software for you on the Internet, enabling you to sign up for an account, $\log$ in to the system, and start blogging straight away. There is a large range of hosted solutions out there, which vary greatly in terms of quality, features and whether you wish to pay for them.

The key advantage of a hosted solution is that you do not need any technical skills or intervention to start blogging. This means that you can get writing immediately and it is a good way to introduce yourself to how blogs work and the mechanics of posting articles and receiving comments.

You will be restricted in terms of the look and feel of the blog - usually in the form of templates provided by the company. You may also be restricted in terms of the functionality a particular blogging software package may provide - whether you can add multiple authors, assign categories to posts or set up more than one blog.

Three of the most popular hosted blogging solutions are:

\section{Blogger/ Blogspot}

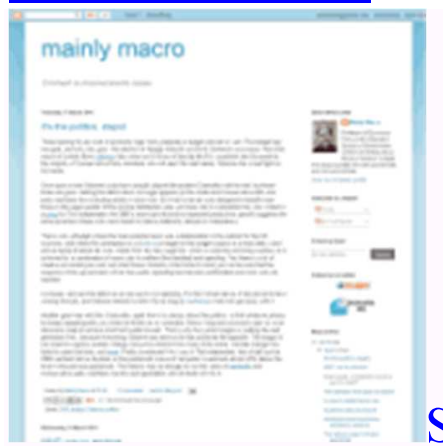

Simon Wren-Lewis' blog, as of March 2016: created in Blogger with a standard template.

Blogger is free and owned by Google - all you need to get started is a valid email address and to register at their website. Perhaps confusingly, Blogger is the 
software but Blogspot is the hosting service, so Blogger sites usually have .blogspot.com in their web address.

Greg Mankiw's (Harvard University) student-focused blog, and Conversable Economist by Timothy Taylor, editor of the Journal of Economic Perspectives, use Blogger.

\section{WordPress.com}

A hosted version of the open source WordPress blogging software (see below), that is free to use and surprisingly rich in features, but some extra features like using your own design template or getting a personalised web address can be paid for.

The Everyday Economist by Josh Hendrickson (of the University of Mississippi) and the Real World Economics Review use WordPress.com

\section{Typepad}

Typepad has a range of pay-monthly options, with the cheapest offering one blog produced by a single author, ranging to a package offering an unlimited number of blogs and unlimited storage.

Economist's View by Mark Thoma of the University of Oregon and Bradford DeLong's (University of California, Berkeley) personal blog are hosted on Typepad.

\section{Institutional options}

Your institution may already provide a blogging platform. Virtual Learning Environments (VLEs) such as Blackboard or Moodle usually come with a blogging module already built in. This has the advantage of being integrated with a system you and your students may already be familiar with, but the functionality is usually less impressive than dedicated blogging software.

Another possibility is that your institution offers its own blogging platform. This is not widespread in the UK, but the University of Warwick and University of Nottingham are among those with their own platform. It may be worth asking your library, computing or information service whether they have a recommended blogging product they support. 


\section{Installed software}
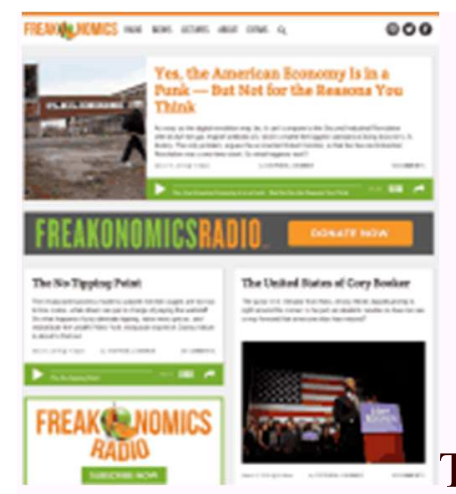

The Freakonomics blog, as of March 2016: a heavilycustomised design using Wordpress software.

The above options will let you set up a blog in minutes, quite easily and for free, depending on the account you choose. If you're happy with that, skip the rest of this section. However, maybe you want not just a choice of designs but total control of the design. Perhaps you don't want adverts on your blog, which commercial services might show. Perhaps you do want adverts, but for your products or for the revenue to come to you. Maybe you want the blog to be integrated with other software. If so, you should consider installing blog software on a server you run, or rent through a commercial web-hosting service.

This will require blogging software (which you can get at no charge), access to a web server on which to host it, and access to the technical skills to configure and manage it all. Once the blog is designed and configured, there is very little ongoing work required, but it is not zero: there will be occasional updates and security fixes to apply.

The intricacies of web server maintenance and the various technical skills needed to run them are outside the scope of this guide, but you could consult within your institution as to what support is available, or look for web hosting companies that include blog software as part of their package.

The present market leader is:

\section{WordPress}

WordPress is an open source blogging platform. It is freely available and has a dedicated community of developers working on new features that can be easily integrated into the software, via plugins or widgets that add extra functionality. The design of the blog can be changed at the click of the mouse, thanks to a library of downloadable themes. 
Marginal Revolution by Tyler Cowen and Alex Tabbarok and The Enlightened Economist featuring book reviews by Diane Coyle of the University of Manchester use WordPress.

The site FirstSiteGuide has a more detailed overview of features of the Wordpress software and what's involved, along with other introductory guides to creating your own blog.

\section{Top Tip}

There are many plugins available for Wordpress. You don't strictly need any: just the Wordpress software is good enough to go. However, two plugins that we recommend are Akismet and Jetpack. They provide incredibly useful services, including spam detection and "social" links (to help readers share your posts), for free. 


\section{Writing and managing content}

Whichever platform you choose, most blogs will have a similar set of features. This part of the guide will tell you about the mechanics of blogging, i.e. how to blog, and some pointers on what you might like to write, i.e. what to blog.

\section{How to Blog}

Like many niche activities, blogging has its own terminology, which may seem off putting to those new to it. A typical blog will have some or all of the following characteristics:

\section{Posts and pages}

You may have options to "Create a new post" and "Create a new page". Both are kinds of web page. Posts are tied to a particular date: these are the main content of your blog. Over time, they will automatically move from your front page to your archive. Pages are more conventional: they will usually have their own buttons in the blog's layout. "About me", "My research", or "My teaching" would go in pages.

\section{Categories and tags}

Categories enable posts to be organised by subjects (or tags) and help readers to find information about a specific topic quickly and easily. Individual posts can be assigned into several categories, often just by ticking a box when writing them.

To bookmark Bradford DeLong's February 2016 post on Obamacare, the link is http://www.bradford-delong.com/2016/02/obamacare-how-is-it-doing.html . Small print at the foot of that post reveals that it has a number of categories, including Political economy. The link for this category is http://www.bradforddelong.com/political_economy/. Rather than a specific piece of text, this bookmark will take the reader to whatever DeLong has recently written on the topic of Political economy.

As you create a blog, create categories for the main topics you write about, and apply at least one category to each post (posts can have multiple categories).

\section{Top Tip}

If a blog post is intended for students on a particular course, use the course code as a category. Then the link for that category will always lead to the latest announcement for that course.

\section{Comments and trackbacks}


Most blogging software allows readers to comment on posts. Readers can suggest corrections, clarify information or simply add their opinion on the post. Comments are normally time-stamped and include the author's name and other details. Another useful feature is that they can also be threaded allowing readers to comment on comments.

When you publish a blog post that links to a post on someone else's blog, your software will automatically send a notification which can appear as a comment on that blog, with a link back to the new post on your blog. This automated message is called a trackback.

\section{Blogroll}

Posts and pages, like other web pages, can contain links. You can also have a list of links as part of the blog design, so it appears on every page and post. This is called a blogroll and it usually directs a reader to interesting links that relate to the theme of the blog. As you find blogs you are interested in, add them to the blogroll for your own and your readers' benefit.

\section{Archives}

Archives are chronological collections of posts, enabling a reader to go back through time and see past posts. They can be arranged by day, week or month, depending on how frequently the site is updated. This is taken care of by the software.

Having a diary of your intellectual activity can be useful if you are involved in a long-term activity, such as doing doctoral research. Going back a few years on your own blog to see what you were learning about or excited about on a particular date, you might be pleasantly surprised at how far you've progressed, or be reminded of an idea that you didn't follow up on.

\section{What to Blog}

Blogging, like other forms of online communication (e.g. email) has its own set of social conventions. It's important to be aware of the following when writing or commenting on blogs:

\section{Think about your audience}

Potentially anything you post can read by a global audience. And a post might be archived or cached and therefore impossible to remove. Think carefully about posting contentious or provocative material, it may spark a rise in readership, but it could make you unpopular online.

\section{Clear communication}


The audience are aware that they are reading something quickly written and published, rather than a proper, reviewed paper. So it's okay to be brief and informal. On the other hand, non-standard abbreviations and too much jargon can put an audience off. Remember that any post might be the first that a reader encounters, so if you are using obscure terminology or extending a prior debate, provide links for context. If there are some technical terms that you use a lot, you might use a page (see above) to create a short glossary.

\section{Credit sources and respect copyright}

Avoid quoting large extracts from a source without the consent of the copyright holder. Credit original authors appropriately: include a link, sometimes called a HatTip, to other bloggers if you are discussing their views.

\section{Correct mistakes and post updates}

Mistakes are inevitable. You might discover them yourself or readers may highlight them. Correcting them adds credibility to your blog and makes it look more professional. If possible, leave the original entry intact and make corrections by adding extra material. Retrospectively deleting text from a blog entry is frowned on, as this may make some of the comments users have posted to your initial article look out of place. Consider using strikeout formatting (like this) to show edits.

\section{Identify yourself and be available}

Try and ensure that your readers can contact you if necessary. If you do post comments on other blogs, it's good practice to identify yourself and provide information about how you can be contacted (usually an email address).

Unattributed comments might be considered as spam. If you don't want a comment to be attributed to you then you should consider whether you really want to make it.

\section{References}

- Giant blogging terms glossary / Quick Online Tips

- How to be heard / Stephen Downes

- List of blogging terms / Wikipedia 


\section{Getting the message out}

So you've published your thoughts online, using one of the methods from Section 2 or Section 3 . If you have a limited audience such as a class of students, just give them the link. Perhaps, though, you want to get your message out as widely as possible. If you're not already a famous blogger, you'll need to do some promotion. Fortunately, you likely already have the necessary tools.

\section{Using online profiles}

Your institutional profile, course pages, and profiles on sites such as IDEAS, Academia.edu or Researchgate.net can all be used to link to your blog.

\section{Using other blogs}

Comments on a post on the Marginal Revolution blog.

Even if your blog is brand new, there is a ready-made audience for it: the people who are already reading other academic blogs on the same topic. They just need to be pointed to your blog via suitable links.

In the previous section we mentioned trackbacks; automatic notifications that appear on the blogs you link to. When you write your post, look for related posts on the blogs you are interested in, and mention them. If those blogs have trackbacks enabled, they will link back to your blog post.

When you comment on someone's blog, you can suggest a link that will appear with the comment. So taking part actively and constructively in the discussion on another blog can direct readers to your own. Parallel to our advice about guest posts in Section 2 , the more your comment connects with the intellectual content of the post, the better. Vacuous comments like "I really like this blog; come and check out mine" smell like spam, and will be ignored or deleted.

It may seem paradoxical, but allowing people to republish your posts is one easy way to get links and visitors to your blog. If your

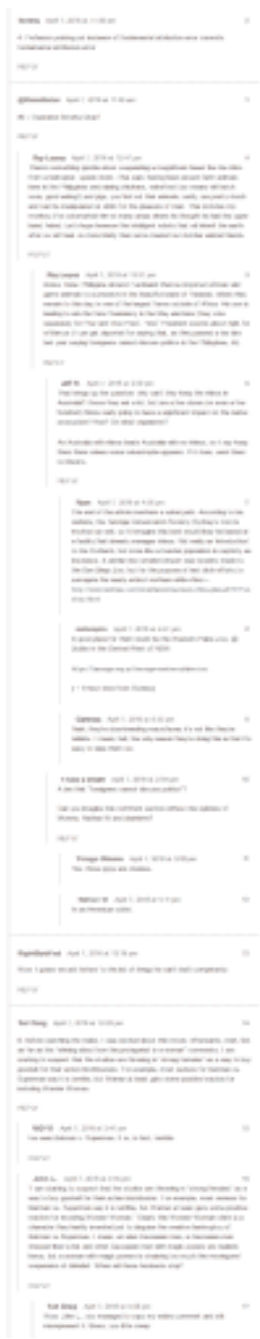
post is interesting enough, other blogs might want to reproduce it with a credit line that links back to the original, so readers get a taster of your writing and a link to find more. Many of the posts on the Impact Blog at the LSE, for example, were originally posted on the author's individual blogs. The easiest way to enable republication, while keeping the right to be credited and linked, is to explicitly give your blog a Creative Commons licence. 


\section{Using email lists}

Mailing lists can annoy all of us, if they get bogged down in long discussion threads that only a few participants are interested in. If the discussion does not need to be private, it can be better to have it in blog comments. That way, the mailing list subscribers just get a link to the discussion and they choose whether or not to visit, rather than having all the messages pushed into their inbox.

Hence it can be a welcome move to head off a bloated email discussion by posting an announcement such as "I've set out my thoughts on this issue on my blog. Comments are open and I welcome responses." Alternatively, "There are a lot of interesting points of view here. I've tried to summarise the different perspectives in a blog post, and I welcome comments if there are points I've missed."

Remember that if you want to quote emails you need to get the author's permission, but people usually respond well to the suggestion that their thoughts deserve a more permanent home and a wider audience.

\section{Using events}

When you're returning from a conference and buzzing with new ideas, you probably want to capture a summary that will be easily findable in future. A blog post is ideal: categories and the archive (see the previous section) make it easy to find your report from a specific conference, and people interested in the conference (whether they managed to attend or not) will welcome your perspective.

Draw the attention of the blog post to the conference organisers, and to speakers that you mention. They will usually welcome a quick, thoughtful reaction and will share it with their audiences.

\section{Using social media}

Micro-blog site Twitter lets its users post messages of up to 140 characters, and to customise which other users are visible. The 140-character limit is not conducive to deep discussion, but it is enough for the title of your latest blog post and its web link. One purpose of Twitter among academics is to get notifications of new blog posts, papers, or events.

\section{Top tip}

Share this:

Email

f Facebook

Google

in Linkedin

Twitter 
Make sure social sharing buttons are enabled on your blog. They make it very easy for readers to share a blog post with their contacts.

If you're already struggling to find the time for blogging, you might not be keen on setting up an account on yet another platform and building up a following. Fortunately, your blog can do your tweeting for you.

Somewhere on your blog is what's called your "feed URL": a web link to a machine-readable version of the most recent posts on the blog. Set up an account on Twitter, create a profile description to identify who you are, then put the Twitter details and feed URL into the free service Twitterfeed. This site will regularly check your blog and, if it finds a new post, will send out a tweet with that post's title and link.

Now you have a Twitter account, post its link on your blog and other profiles, so your readers who use Twitter can subscribe for notifications whenever you write a new post. 


\section{Risks}

In the early years of the 21 st century, blogging was seen as a risky proposition that, at best, would take away from the time you spend on your research and teaching. Since then, universities and scholarly societies have taken on blogs and social media more generally as a way to engage all sorts of audiences.

Regular blogging does not seem to have hurt the careers of Paul Krugman or Yanis Varoufakis. It has not apparently diminished the influence of Mariana Mazzucato or Larry Summers. The enthusiasm for blogging amongst popular authors including Tim Harfordand David Smith suggests that sharing small, topical pieces of your writing does not hurt book sales either.

The change in academic attitudes is best exemplified by the Impact Blog at the LSE. Originally intended as a short-term project about the impact of social sciences, it has become a focal point for discussion about the process of scholarly publication in many different disciplines, including lots of advice and opinion about academic blogging itself.

The biggest risk is of non-involvement; of being invisible in this open, fast-moving space where public discussion and scholarly discussion of your subject overlap. Still, there are some potential downsides to consider before you leap fully into blogging.

\section{Effect on your job, or your next job}

People have lost jobs as a consequence of what they have written on their blogs, even if they have taken care not to refer directly to their employers and have blogged under pseudonyms. You should bear in mind that your current or any prospective future employer may find your blog online and take it into account when assessing your employability.

\section{Relationship with your institution}

If your blog is set up within a Virtual Learning Environment or an institutional blog hosting service, it will be clear that you will be writing as a member of your university or college. This means that you will be subject to the relevant code of conduct or appropriate use of computing resources policy for your institution. While few institutions have a policy specifically to cover blogging, should you feel restricted by any limits these policies place upon your writing, you may wish to blog outside the confines of the IT systems provided for you by your institution. 


\section{Intellectual property}

A blog may be a useful forum for floating new ideas, theories or areas of research, but it is not usually a formal project output. It is not clear whether ideas expressed or published on a blog, are covered by the same rules and regulations as a book, article or other output produced while you are an employee of an institution or being funded by a research grant.

Republication of your posts on other sites may be something you want to prevent, or something to actively encourage, so long as you are given credit and a link. Put a copyright statement or a Creative Commons licence prominently on your blog so readers know which further uses of the text are allowed.

\section{Blog ethics}

Blogs come with their own set of social rules or blog etiquette. For example, any online source cited or quoted in your posts should be acknowledged with a link. Retrospectively editing a blog entry is frowned on, as this may make some of the comments users have posted to your initial article look out of place. Consider using strikeout formatting (like this) to show edits or make additions to the bottom of a post to show how your views may have evolved.

\section{Comments}

The default setting for most blogs is to allow comments from readers. While this can lead to fruitful interactions, debate and links to useful further resources, like any open form of conversation, it can lead to inappropriate or offensive comments and Internet marketers will try to "spam" your blog with vacuous comments linking to their sites. Blogging software has tools to defend against most spam, as explained in an earlier section.

You may wish to investigate the security options in your blogging software. You could require readers to register before posting a comment to your blog, or hold comments in a queue for your approval before they are published.

\section{Other legal issues}

The Electronic Frontier Foundation has produced a Legal Guide For Bloggers, which looks at some of the key legal issues that affect blogs. However, it should be remembered that this has been written from an American perspective and therefore some of the advice would not necessarily apply elsewhere. Also, this is an area of law that is developing all the time, so what may be true today could be changed by a new piece of legislation in the near future. 


\section{References}

- Bloggers need not apply / Ivan Tribble - Chronicle of Higher Education 8 July 2005

- Blogging theory / Jodi Dean (2006)

- Blogging while untenured and other extreme sports / Christine Hurt, Tung Yin (2006)

- Confessions of a scholar blogger / Daniel Drezner (2005) University of Chicago Magazine, v. 97, issue 3

- Serious bloggers / Jeff Rice - Inside Higher Education 20 February 2006

- The relationship of blogging to academic work / N Pepperell (2005)

- By the blog: academics tread carefully / Zoe Corbyn - Times Higher Education, 9 October 2008 


\section{Uses for Economics}

Henry Farrell is an Assistant Professor at the Department of Political Science and the Elliott School of International Affairs of George Washington University, and he is also one a group of scholars who contribute to the Crooked Timber blog. He has identified five uses of blogs within the classroom:

- replacing standard class web pages

- professor-written blogs which cover interesting developments that relate to the theme of the course

- organization of in-class discussion

- organization of intensive seminars where students have to provide weekly summaries of the readings

- requiring students to write their own blog posts as part of their grade

Canadian learning technologist Stephen Downes has expanded on these uses in an article for the EDUCAUSE Review.

But what is the potential for blogging in Economics teaching? Steve Greenlaw of the University of Mary Washington explores the broader role of technology in teaching via his blog Pedablogy: musings on art and craft of teaching.

A series of specific examples are presented below:

\section{Replacing standard class web pages}

Have you ever struggled to craft your own course website? It can be a valuable aid, enabling you to post suggested readings, set tasks / exercises / assignments or just remind students when they are expected to turn up for lectures. Using a blog can let you concentrate on adding the information, rather than having to learn additional IT skills.

This is something that Tim Kochanski at the University of Alaska Southeast successfully trialled. He created a blog as part of a four-week class on introductory economics. He was keen to investigate a low-cost alternative to using his institutional course management system (Blackboard). He found that the journal format of a blog, as well as other features provided a valuable resource to help guide his students through a semester of economics. A detailed case study is available in the Economics Network's Ideas Bank.

\section{Professor-written blogs which cover interesting developments that relate to the theme of the course}

You may already be finding things online that are relevant to your teaching. A blog can enable you to bring these resources together, comment on them and organise 
them in a manner which may be helpful to your students. You may want to try and make the theoretical aspects of what you are teaching meaningful in a broader context, by highlighting items of topical interest.

The Tutor $2 \mathrm{u}$ website is a good example of this. It offers a range of subject-specific blogs. Geoff Riley (Head of Economics at Eton College) maintains the Economics Blog and provides a regular commentary on economics issues and trends. Although the primary target audience is secondary school students some of the resources could be useful in first year undergraduate courses on introductory economics.

\section{Organization of in-class discussion or seminars}

You may have experimented in the past with discussion boards and found that they can produce useful dialogues. Opening up this process with a group blog can enable students to post items, comment on them, get to know each other and even answer their own questions. You may get contributions from students who find face-to-face discussion difficult, but who find online communication more suited to their learning style.

David Tufte manages an 'Economics Classes Blog' at Southern Utah University:

His students regularly post items of interest and ask thought provoking questions. Tufte then invites his students to offer their feedback/analysis on that particular economics issue, by placing comments on the blog, where he occasionally offers comments of his own to relate the items to ideas he has mentioned in class. 


\section{Conclusion}

"I'll publish, right or wrong" (Byron)

This guide has outlined the possibilities that blogs offer in terms of teaching, personal and professional development, and engaging with a global audience. The chance to take advantage of an "invisible college" of fellow scholars, informed readers and actively engaged students, means that blogs can provide a whole new dimension of interaction in helping people make sense of economic issues. Using blogs as part of the classroom experience can take the technical strain out of producing a website and allow you to concentrate on writing, discussing and teaching online.

We hope that this short guide has made you aware of the mechanics of blogging and some of the potential pitfalls, given you some ideas as to how you could use them for economics teaching and opened your eyes to some of the future possibilities that blogging as a technology can offer. If you successfully build blogging into your normal work routine, you may soon find that blogging starts to take over your life and that it is increasingly difficult to live without your virtual notebook.

The freedom that blogs bring to the voiceless in politically repressive regimes is a good example of how blogs enable anyone to publish anything online. The chance to hear from alternative viewpoints, to publish ideas that may not get an airing elsewhere, to sidestep the mainstream media and to experience quality writing freely and openly, means blogs can help produce a genuine free market in ideas. 